\title{
Design of FRP belts for building retrofitting
}

\author{
Oleg Simakov* \\ Moscow State University of Civil Engineering, Yaroslavskoye Shosse, 26, Moscow, 129337, Russia
}

\begin{abstract}
The article gives recommendations on the calculation and design of the restoration of bearing capacity of the buildings that have significant deformations of the walls from brickwork. The method with the use of fibre-reinforced plastic (FRP), is a composite material made of a polymer epoxy matrix reinforced with carbon fibres. In addition, the accumulated experience, based on the results of the tests (static and dynamic on the fragments of structures and mock-ups of buildings) is considered, as ell as the applications on the real objects.
\end{abstract}

\section{Introduction}

Damage to load-bearing structures often occurs during the operation of the buildings with the load-bearing walls of URM. These damages, caused mainly by the deformations of the base or dynamic influences, reduce the strength, stability, durability and operational reliability both the entire building and the individual fragments (structures).

To restore the initial, necessary level of the bearing capacity of the building, it is necessary to perform reinforcement of the structures that have suffered. For this purpose, special measures are taken to minimize the impacts that lead to destruction (often the reinforcement of foundations). Besides the strengthening of the damaged structures, the measures to increase/restore the overall rigidity of the building are taken.

One of the methods of increasing the overall stability of the building is the device of external closed belts. Typically, these belts are made of formed steel construction or strips. Belts made of steel elements have a number of significant drawbacks, that can be excluded by the use of composite materials on the basis of the carbon fibers - the material of high strength, non-corrosive with small dimensions and weight.

\section{Applications}

The general cause of deformation and damage to the bearing walls from masonry is the uneven sedimentation of the ground base. Uneven precipitation, as a rule, occurs due to the local soaking of the soil caused by man-made or storm sewage, and affects the individual parts of the building. The following structural damages are observed:

- vertical cracks alongside the walls in the upper or lower part of the building;

- destruction of the inter-partition walls;

\footnotetext{
* Corresponding author: simakovoa@mgsu.ru
} 
- deviation from the vertical of individual walls or their sections.

There are 3 types of the building deformations:

a) The deflection

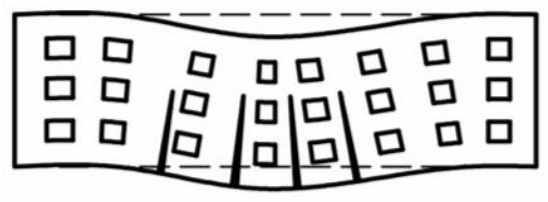

Characteristic cracks are vertical, distributed in the lower middle part of the building

b) The inflection

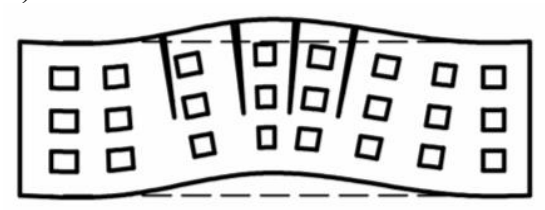

Characteristic cracks are vertical, distributed in the upper middle part of the building

c) The skewness

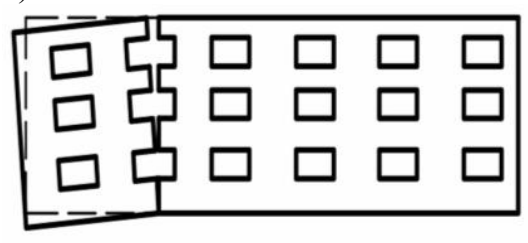

The characteristic cracks are vertical with the concentration in separate area.

In the presence of the above cracks, the building is conditionally divided into separate fragments with a significant reduction in the overall spatial rigidity. In this case, the fragments of the building should be considered separately with the formulation of the equilibrium equation for each of the fragments separately $[1,2]$.

The method of the installation of the steel belts along the perimeter of the building has been used for a long time to restore the initial stability of the building and unite the separated fragments,

This method involves the installation at the level of overlapping, as well as the covering of the steel elements covering the building alongside the perimeter (for complex (in terms of) buildings, the building is divided into separate blocks with (in plan) a simple form of a rectangle). After installation, the belts impede the perception of forces caused by the subsidence. In addition, the overall stability of the building is increased, as a result of which the loads are redistributed to the ground base and the deformations alongside the building area are leveled.

The use of steel elements to create these belts has a number of drawbacks, such as:

- corrosion of steel elements;

- thermal bypasses when mounted in the body of the wall (the arrangement of niches);

- there is change the appearance of the building when mounted along the wall plane;

- there are laborious works on the installation, transportation of materials.

As part of the development of this method and elimination of the disadvantages inherent in steel structures, it is proposed to use composite materials on the basis of the carbon fibers.

The use of composite materials makes it possible to exclude the main labor-intensive processes for the construction of niches, the lifting of heavy structures, the device of holes for anchoring elements, and these materials do not change the appearance of the building and are not subject to corrosion. 


\section{Experimental studies}

Numerous experimental studies have been carried out to increase the load-carrying capacity of the structures from masonry, as well as fragments of buildings [3-7].

Among the studies of bond should be highlighted [3 - 6]. Experimental studies were carried out on fragments of structures - piers, suspension towers made of bricks and largeformat stone (fig. 1).
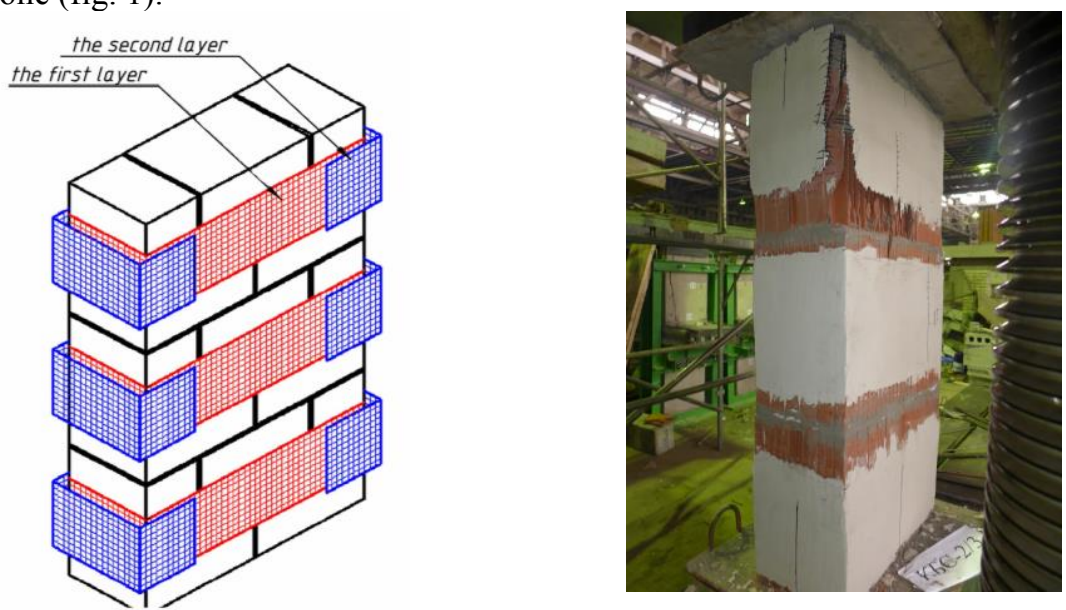

Fig. 1. The test samples.

Also it is possible to allocate [4] - tests of real models of buildings from a stone laying (fig. 2).
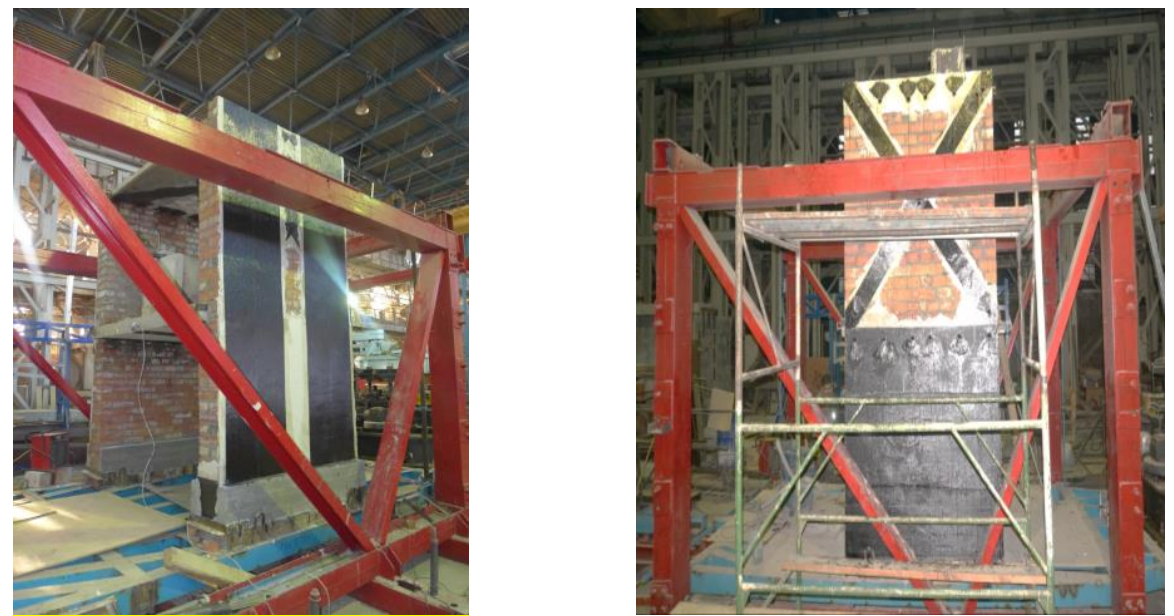

Fig. 2. The test samples.

These tests showed the predicted reliable performance of FRP in the zone of design loads. This applies to static and dynamic loads. The only drawback is a fragile failure when the ultimate load is reached.

Based on the results of the tests, the refined coefficients for the developed theory of calculation of structures from bond were obtained. The constructive decisions on the application of FRP with the strengthening of masonry have been finalized. 
The possibility of using FRP on the objects located in the seismic areas is experimentally confirmed.

\section{Principles of calculation and design}

The problem of solving the equation of equilibrium of a system underlies the design of reinforcement belts in accordance with Fig. 3 .

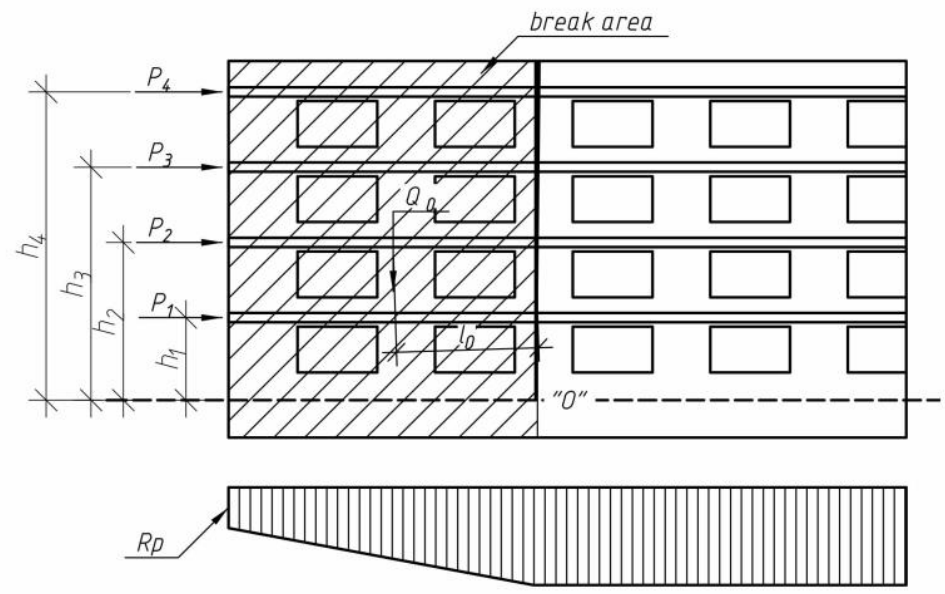

Fig. 3. The design scheme for the definition of the efforts in the belts.

To solve this problem at the initial stage determine the value of the design resistance of the soil in the damaged zone $R_{p}$ by the formula

$$
R_{p}=0.8 \mathrm{Ko} / \mathrm{K}_{l}
$$

where $\mathrm{R}$ is the design resistance of the soil in an undamaged area of the base; K0 is coefficient of soil reaction on the weakened portion of the base; K1 is coefficient of soil reaction on an undamaged area of the base [1].

Efforts in the belts (P1, P2, P3 .... Pi) are obtained from the solution of the system of equations of equilibrium with respect to the point "O". The position of the "O" point is determined from the lower boundary of the crack. Based on the effort, the required section of the belts is calculated.

The calculation is carried out taking into account the joint operation of external reinforcement and bond. The strength of the belts in this case is determined by the formula

$$
P \leq R f \cdot A f
$$

where $P$ is the calculated axial force when the element is stretched $(\mathrm{kH}) ; R f$ is the tensile strength of the composite material $(\mathrm{kN} / \mathrm{mm} 2)$ by the formula (3) [8]; Af is the crosssectional area of the composite material ( $\mathrm{mm} 2)$.

$$
R f=E_{f} \cdot \varepsilon f e
$$

where $\varepsilon f e$ is the estimated tensile strain.

$$
\varepsilon_{f e}=0.45 \cdot \varepsilon f u
$$

where $\varepsilon_{f e}$ is the estimated tensile strain. 
$\varepsilon f u$ is the ultimate deformation of the fibrous plasters rupture is determined by the passport data for the composite material.

A separate case is the calculation of the loss of stability of walls from brickwork from the plane (see Fig. 4)

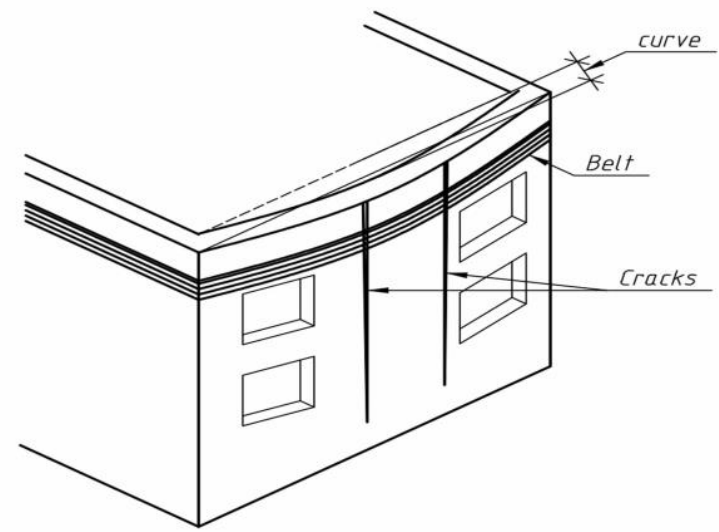

Fig. 4. The loss of stability of walls from brickwork from the plane.

This case is calculated according to the following scheme (Fig. 5)

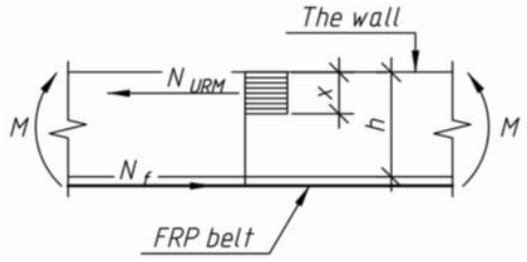

Fig. 5. The rated cross-section of the wall

The normal moment capacity of a FRP strengthened masonry wall out of plan loading can be calculated from Eq. (5).

$$
\begin{aligned}
M \leq & R_{U R M} \cdot x \cdot(w+h) \cdot(h-x / 2) \\
& x=\left(R_{f e} \cdot A_{f}\right) /\left(R_{U R M} \cdot(w+h)\right)
\end{aligned}
$$

where $R_{f e}$ is the effective stress in the fibrous plasters of carbon fiber, taking into account the magnitude of the ultimate deformation on the contact "fibrous plaster is bond material" is determined by the Eq. (3), according $R_{f e}=R_{f}$,

RURM is the strength of masonry;

$(w+h)$ is the width of the compression area of masonry ( $w$ - width of the FRP belt).

Taking into account possible variants of destruction of the element of reinforcement of the masonry by the composite material (decomposition of the bond under compression, detachment of the fibrous plaster from the bond), the limiting deformations of the carbon fiber are limited to the following dependence (4).

While designing reinforcement belts from FRP, it is necessary to take into account the need for preparation of the base (bond surface) consisting of: 
- dismantling of damaged and fragile layers of bond;

- restoration of the destroyed zones with provision of anchoring to the base layer (achieved by using special anchors);

- repair of cracks (sealing of cracks with a width of more than $0.2 \mathrm{~mm}$ );

- maintence leveling of the surface under the label (FRP is mounted on a flat surface, the surface roughness should not exceed $5 \mathrm{~mm}$ on the basis of $2 \mathrm{~m}$ or $1 \mathrm{~mm}$ on a base of 0.3 $\mathrm{m})$.

Besides, it is necessary to round the corners in accordance with Fig. 6 and reinforce with additional ribbons with a cross-sectional area of at least $25 \%$ of the required by the calculation.

Fig. 6. The necessary corners.
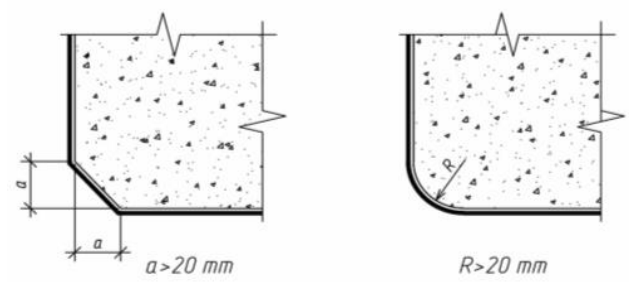

The length of the anchoring of FRP elements when docked to the cover is at least $2 \mathrm{w}$ (where $\mathrm{w}$ is the width of the tape). Joints is to be disposed, preferably in the zone with minimal effort.

After performing the installation of FRP, it is necessary to carry out measures for applying a protective and decorative coating (plastering or painting).

If the above requirements are taken, the external reinforcement system will operate reliably for at least 50 years (based on accelerated tests).

\section{Experience}

The accumulated data of the experimental studies, as well as the developed methods of calculation and design, made it possible to apply FRP on specific objects.

One of such objects is an administrative building in the village of Volodarsky, Kazakhstan.

As a result of long-term operation, the movement of the soil foundation, the building received a significant defect in brick structures - numerous cracks and destruction of the whole fragments of the wall bond.

As a result of repair work, the geometry of the masonry was restored and reinforcement with FRP carbon bands was carried out. With this reinforcement, measures to strengthen the foundations were not carried out, only the overall stability of the part of the building was raised.

After 4 years of operation defects and structural damages, were not revealed (Fig. 7). 


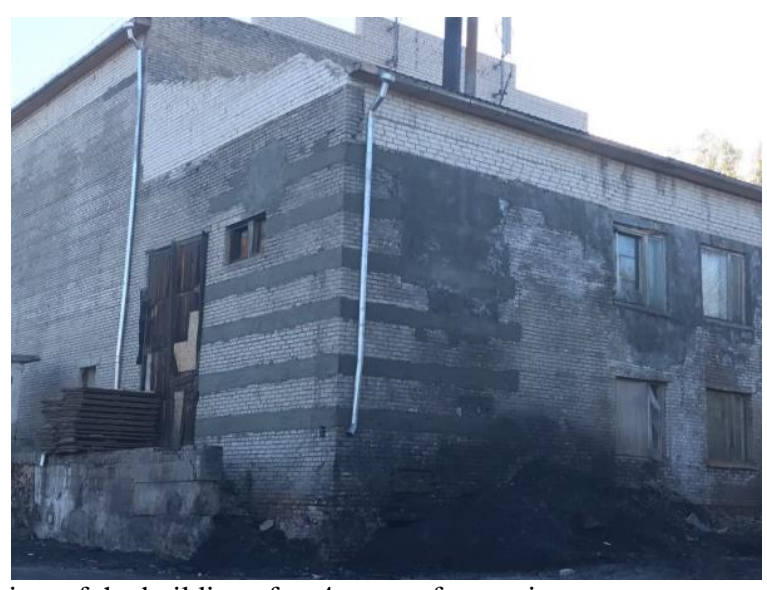

Fig. 7. The general view of the building after 4 years of operation

In addition to this object more than 30 objects are strengthened by belts from FRP at the present time. Some of them are monitored every 2 years. Up to now, defects and damages have not been fixed at any of the objects, which allows to speak about the sufficient reliability of this method of amplification.

\section{Conclusions}

The conducted experimental studies, as well as the use of reference objects, allow us to draw the following conclusions about the use of FRP strips in strengthening the buildings with bond structures:

1. The use of FRP allows to increase the load-bearing capacity of structures from bond (in some cases up to 2 times) and the building as a whole. The increase in loadbearing capacity can be determined by performing special calculations based on test results.

2. The destruction of bond occurs, usually, at stresses in the masonry close to the durability of the brick. In this case, the use of special anchoring fasteners allows to exclude the detachment of FRP from the surface.

3.FRP is efficient in improving the performance of URM walls subjected to out-ofplane loads. Calculation provisions and special formulas are defined for this case.

4. The experience of using belts from FRP allows us to begin mass application of this method on objects of different levels of responsibility, as well as located in seismically dangerous areas. Calculation of forces in the element belts in this case is carried out in accordance with the equations of structural mechanics, limiting stresses are limited to the value of adhesion to bond.

\section{References}

1. V. Khortsev, D. Proskura, D. Gura, G. Shevchenko, Sbornik «Nauki o Zemle na sovremennom etape», 116 (2012)

2. V. Ledenev, V. Odnolko, A. Kolesnikova, Vestnik TGTU, 20/1, 141 (2017)

3. A. Granovsky, B. Dzhamuev, V. Polykov, A. Kachnovsky, O. Simakov, P. Osipov, Vestnik SRC «Stroitelstvo», 3, 21 (2017)

4. A. Granovsky, B. Dzhamuev, O. Simakov, P. Osipov, PGS [Industrial and Civil Engineering], 4, 44 (2017) 
5. A. Granovsky, B. Dzhamuev, A. Dottuev, PGS [Industrial and Civil Engineering], 5, 31 (2016)

6. A. Granovsky, B. Dzhamuev, O. Simakov, PGS [Industrial and Civil Engineering], 9, (2017)

7. L. Tong, N. Galati, J.G. Tumialan, A. Nanni, TMS Journal December, 47 (2005) 